THURSDAY, SEPTEMBER 19, 1912.

\section{CHEMICAL TECHNOLOGY.}

(I) Bleaching and Dyeing of Vegetable Fibrous Materials. By Julius Hübner. With an Introduction by Prof. R. Meldola, F.R.S. Pp. xxiii + 434. (London : Constable and Co., Ltd., rgr2.) Price $14 s$. net.

(2) German Varnish-making. By Prof. Max Bottler. Authorised Translation with Notes on American Varnish and Paint Manufacture. By A. H. Sabin. Pp. vii +363 . (New York: John Wiley and Sons; London: Chapman and Hall, Ltd., I912.) Price I $_{5}$ s. net.

(3) Allen's Commercial Organic Analysis. Edited by W. A. Davis and S. S. Sadtler. Fourth edition. Entirely re-written. Vol. vi. $\mathrm{Pp}$ ix +726 . (London: J. and A. Churchill, I9I 2.) Price 2 Is. net.

(I) THIS is a practical manual intended for the 1 use of students and junior employees. The purely scientific aspect of bleaching and dyeing is not within the scope of the work. As Prof. Meldola remarks in an interesting introduction, Mr. Hübner knows the theoretical side of the industry as well as anybody does . . . but his present treatment of his subject is not intended to supersede but to superadd to the scientific treatment. About one-third of the book is devoted to the description of bleaching operations, including some preliminary sections dealing with the materials employed, namely, the textile fibres, water, chemicals, and mordants. After a few pages on mercerising, the rest of the space is allotted to the discussion of dyestuffs and dyeing procedure. Practical directions for carrying out the operations are given, and frequently different methods of applying the same dyestuffs are adduced for purposes of comparison. There are numerous illustrations, chiefly of sections of machinery; and a feature of these is that in many cases they are made much more intelligible than usual by the use of a two-colour device to show the course of the fabric through the machine. The book can be cordially recommended as a concise and up-to-date compilation of practical information.

(2) Mr. Sabin is an enthusiast on the subject of paints and varnishes, and his translation of Prof. Bottler's book is far from being dry reading. The original is too concise and brief, in the translator's opinion; he has therefore added a number of notes en passant. These are printed distinct from the main text, and include useful bibliographical references, explanatory comments, and extensions of matters mentioned in the original or suggested by it. For example, when resenes are first referred to (as constituents of copal and other resins), Mr. Sabin interpolates a brief account of their properties, with a reference and a criticism. Hence the work may be looked upon as giving the German practice in varnish-making, annotated from the American point of view. But in addition to the running notes, Mr. Sabin contributes whole chapters also; one upon miscellaneous points in the manufacture of varnish, and one on the nature and constitution of paint; there is, further, a useful appendix of notes and references on analytical methods employed in the examination of varnishes. It is worthy of remark that, according to the translator, "our (i.e., the American) methods are based upon English practice, and the English alone among foreign nations are still able to sell varnish here against our best makers."

(3) The general characteristics of the new edition of Allen's "Commercial Organic Analysis" are now tolerably familiar to users of the work, and in this connection it need only be noted that the sixth volume follows much the same lines as its predecessors. It is concerned with the chief organic bases and the alkaloids. All the latter, however, are not dealt with, some being relegated to the succeeding volume. The amines, anilines, naphthylamines, and their allies are discussed by Messrs. Davis, Sadtler, and Glover respectively. In dealing with the alkaloids, the plan has been to have first a general description of the vegetable alkaloids (this is contributed by Dr. Henry), and then to have the various groups of these products dealt with by special contributors.

It is perhaps invidious to single out any sections where all appear to be well done, but mention may be made of the articles on the volatile alkaloids and the opium group by Mr. F. O. Taylor; those on the aconite alkaloids and on atropine and its allies by Mr. F. H. Carr; and that on the cinchona group by $\mathrm{Mr}$. Oliver Chick. The section on caffeine, tea, and coffee, by Messrs. Fox and Sageman, is a very useful contribution, as is also that on cocoa and chocolate by Mr. Whymper; the former is illustrated with photographs of leaves said to have been used as adulterants of tea, and by some diagrammatic sketches showing the microscopic structure of tea, coffee, and chicory.

The descriptions of the theoretical chemistry of the various products dealt with in the book appear to be trustworthy, and it is a convenience to have them in conjunction with the analytical working details. A little more careful proofreading would have detected a number of misprints. 